\title{
Cervical disc replacement: examining "real-world" utilization of an emerging technology
}

\author{
Christopher D. Witiw, MD, MS, ${ }^{1,2}$ Fabrice Smieliauskas, PhD, ${ }^{3,4}$ Sandra A. Ham, MS, ${ }^{5}$ and \\ Vincent C. Traynelis, MD ${ }^{6}$
}

'Division of Neurosurgery, Department of Surgery, University of Toronto; 'Li Ka Shing Knowledge Institute, St. Michael's Hospital, Toronto, Ontario, Canada; Departments of ${ }^{3}$ Economics and ${ }^{4}$ Pharmacy Practice, Wayne State University, Detroit, Michigan; ${ }^{5}$ Center for Health and the Social Sciences, The University of Chicago; and ${ }^{6}$ Department of Neurological Surgery, Rush University Medical Center, Chicago, Illinois

\begin{abstract}
OBJECTIVE Cervical disc replacement (CDR) has emerged as an alternative to anterior cervical discectomy and fusion (ACDF) for the management of cervical spondylotic pathology. While much is known about the efficacy of CDR within the constraints of a well-controlled, experimental setting, little is known about general utilization. The authors present an analysis of temporal and geographic trends in "real-world" utilization of CDR among those enrolled in private insurance plans in the US.
\end{abstract}

METHODS Eligible subjects were identified from the IBM MarketScan Databases between 2009 and 2017. Individuals 18 years and older, undergoing a single-level CDR or ACDF for cervical radiculopathy and/or myelopathy, were identified. US Census divisions were used to classify the region where surgery was performed. Two-level mixed-effects regression modeling was used to study regional differences in proportional utilization of CDR, while controlling for confounding by regional case-mix differences.

RESULTS A total of 47,387 subjects met the inclusion criteria; 3553 underwent CDR and 43,834 underwent ACDF. At a national level, the utilization of single-level CDR rose from 5.6 cases for every 100 ACDFs performed in 2009 to 28.8 cases per 100 ACDFs in 2017. The most substantial increases occurred from 2013 onward. The region of highest utilization was the Mountain region (Arizona, Colorado, Idaho, Montana, Nevada, New Mexico, Utah, and Wyoming), where 14.3 CDRs were performed for every 100 ACDFs (averaged over the 9-year period of study). This is in contrast to the East South Central region (Alabama, Kentucky, Mississippi, and Tennessee), where only 2.1 CDRs were performed for every 100 ACDFs. Patient factors that significantly increased the odds of undergoing a CDR were age younger than 40 years (OR 15.9 [95\% Cl 10.0-25.5]; $p<0.001)$, no clinical evidence of myelopathy/myeloradiculopathy (OR $1.5[95 \% \mathrm{Cl}$ 1.4-1.7]; $p<0.001$ ), and a Charlson Comorbidity Index score of 0 (OR 2.7 [95\% Cl 1.7-4.2]; $p<0.001)$. After controlling for these factors, significant differences in utilization rates remained between regions (chi-square test $=830.4 ; p<$ 0.001).

CONCLUSIONS This US national level study lends insight into the rate of uptake and geographic differences in utilization of the single-level CDR procedure. Further study will be needed to ascertain specific factors that predict adoption of this technology to explain observed geographic discrepancies.

https://thejns.org/doi/abs/10.3171/2019.10.SPINE19919

KEYWORDS cervical disc replacement; cervical fusion; cervical spondylosis; real-world; utilization

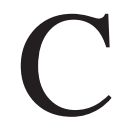

ERVICAL disc replacement (CDR) has emerged as a promising alternative to anterior cervical discectomy and fusion (ACDF) for the management of cervical spondylotic pathology. ${ }^{13}$ The first of these CDR devices to gain approval from the US Food and Drug Administration (FDA) was the Prestige ST Cervical Disc
System (Medtronic) in 2007. ${ }^{12,20}$ Subsequently, numerous other devices have been FDA approved..$^{13}$

As a part of this process, high-quality evidence has emerged from well-conducted, prospective Investigational Device Exemption studies. The results generally suggest long-term efficacy of single-level CDR in comparison to

ABBREVIATIONS ACDF = anterior cervical discectomy and fusion; CDR = cervical disc replacement; CPT = Current Procedural Terminology; FDA = Food and Drug Administration. 
ACDF for appropriately selected patients. In particular, these studies support comparative efficacy using outcomes of the Neck Disability Index, Neck Pain Rating, 36-Item Short Form Survey composite health scores, sagittal angular motion, and reoperation rates. ${ }^{5}$

While much is known regarding the efficacy of CDR within the constraints of a well-controlled experimental setting, comparatively little is known about the adoption of this technology in the general patient population. To address this knowledge gap, we present a descriptive epidemiological analysis of temporal trends and regional differences in "real-world" adoption of CDR for single-level cervical spondylotic pathology among a large recent cohort of enrollees in private insurance plans in the US.

\section{Methods \\ Data Source}

Eligible subjects were identified from the IBM MarketScan Commercial and Medicare Supplemental Databases (IBM Watson Health) from January 2009 through December 2017. These databases contain all claims, paid and adjudicated, at an individual level for enrollees in employer-sponsored health plans, as well as retirees with Medicare supplemental insurance. ? This is the largest segment of American healthcare users, and MarketScan includes claims for 25-50 million enrollees per year. MarketScan has been found to be well representative of commercially insured patients when compared with the Medical Expenditure Panel Survey.,

\section{Study Eligibility}

Individuals 18 years of age and older, undergoing a single-level CDR or ACDF for cervical radiculopathy and/or myelopathy, were identified using a combination of American Medical Association Current Procedural Terminology (CPT) codes and ICD codes (9th and 10th revisions [ICD-9 and ICD-10]). Those with CPT code 22856 were flagged for the CDR cohort. The ACDF cohort comprised those with CPT code 22551, 22554, or 63075. Of those flagged for inclusion in the ACDF cohort, only individuals with an appropriate combination of ACDF codes (either 22551 independently or 22554 concurrent with 63075) were retained as eligible. This was done to account for a change in the coding profile in 2011 that saw the introduction of code 22551 and the elimination of code 22554.

Following this initial case screen, additional CPT codes were used to exclude all cases with concurrent cervical spinal procedures. This comprised any individuals undergoing multilevel anterior procedures, corpectomy, posterior spinal procedures, or any trauma-related spinal procedure. Next, any individual who did not have an ICD9 or ICD-10 diagnostic code for cervical radiculopathy and/or cervical myelopathy was excluded to ensure appropriate surgical indications. Furthermore, any individual with an ICD-9 or ICD-10 diagnostic code for neoplasm, trauma, infection, pathological fracture, rheumatological condition, or syrinx was excluded to mitigate potential confounding factors that may bias the surgical decisionmaking process. See Supplementary Table 1 for a full description of all codes used to determine study eligibility.
Finally, any subject with less than 6 months of presurgical enrollment was excluded. This step ensured sufficient time for the identification of comorbidities.

\section{Model-Level Covariates}

Patient-level covariates included age, sex, Charlson Comorbidity Index score, neurological diagnosis (radiculopathy or myelopathy/myeloradiculopathy), smoking status, and osteoporosis. The region of surgery was classified using the 9 official US Census Bureau divisions. ${ }^{16}$

\section{Statistical Analysis}

The sample data set was constructed using SAS 9.4 (SAS Institute Inc.) and further refined using Stata 15 (Stata Corp.). All statistical comparisons are performed using $\mathrm{R}$ version 3.2.3 (R Foundation for Statistical Computing). Raw data are presented using descriptive statistics, continuous variables as means with standard deviations, and dichotomous or categorical data as frequencies and percentages. Comparisons of continuous data were tested using unpaired t-tests and categorical data comparisons with chi-square tests. Temporal differences in utilization were calculated using the asymptotic general independence test from the R package coin (https://cran.r-project.org/web/ packages/coin/coin.pdf). The break point where the most substantial change in utilization occurred was estimated using the R package segmented (https://cran.r-project.org/ web/packages/segmented/segmented.pdf). A two-level mixed-effects logistic regression model with individuals nested within regions was constructed using the $\mathrm{R}$ package lme4 (https://cran.r-project.org/web/packages/lme4/ lme4.pdf). The model includes a random intercept for the region where the surgery was performed and fixed effects for individual-level patient covariates, which serves to control for potential regional case-mix differences. These fixed-effects covariates included age, sex, neurological diagnosis (radiculopathy vs myelopathy/myeloradiculopathy), Charlson Comorbidity Index score, osteoporosis, and smoking status. The significance of the regional effect was tested using the likelihood ratio test, comparing the mixed-effects model with a model composed of only the fixed-effects covariates. The level for accepting statistical significance was set using a two-sided alpha value of 0.05 .

\section{Research Ethics Board Approval}

The study was approved by the institutional review board at The University of Chicago.

\section{Results}

In total, 3553 subjects were included in the CDR cohort and 43,834 in the ACDF cohort. Univariate comparison between the groups reveals a significantly lower mean age, lower prevalence of myelopathy, lower burden of comorbidities, and lower prevalence of osteoporosis in the CDR cohort (Table 1).

\section{Time-Based Trends}

Within our data set, the frequency with which singlelevel CDR was performed compared with ACDF rose sig- 
TABLE 1. Descriptions of the CDR and ACDF samples from the MarketScan Research Databases between 2009 and 2017

\begin{tabular}{lrrr}
\hline \multicolumn{1}{c}{ Variable } & $\begin{array}{c}\text { CDR } \\
(\mathrm{n}=3,553)\end{array}$ & $\begin{array}{c}\text { ACDF } \\
(\mathrm{n}=43,834)\end{array}$ & $\mathrm{p}$ Value \\
\hline Mean age, yrs & $44.4 \pm 8.8$ & $49.7 \pm 10.2$ & $<0.001$ \\
\hline Age categories, yrs & & & $<0.001$ \\
\hline $18-40$ & $1,185(33 \%)$ & $8,197(19 \%)$ & \\
\hline $40-50$ & $1,516(43 \%)$ & $15,493(35 \%)$ & \\
\hline $50-65$ & $836(24 \%)$ & $17,671(40 \%)$ & \\
\hline$>65$ & $20(1 \%)$ & $2,517(6 \%)$ & \\
\hline Male & $1,673(47 \%)$ & $20,757(47 \%)$ & 0.768 \\
\hline Myelopathy & $674(19 \%)$ & $11,590(26 \%)$ & $<0.001$ \\
\hline Charlson Comorbidity Index & & & $<0.001$ \\
score & & & \\
\hline 0 & $2,789(78 \%)$ & $30,528(70 \%)$ & \\
\hline 1 & $645(18 \%)$ & $9,634(22 \%)$ & \\
\hline 2 & $104(3 \%)$ & $2,550(6 \%)$ & \\
\hline$>2$ & $19(1 \%)$ & $1,162(3 \%)$ & \\
\hline Current smoker & $327(9 \%)$ & $4,419(10 \%)$ & 0.099 \\
\hline Osteoporosis & $112(3 \%)$ & $1,950(4 \%)$ & 0.001 \\
\hline
\end{tabular}

Values are expressed as the number (\%) of patients unless otherwise noted. Boldface type indicates statistical significance.

nificantly between 2009 and 2017 (chi-square $=6.4 ; \mathrm{p}=$ 0.01 ). In 2009, the utilization rate of CDR was 5.6 cases for every 100 ACDFs performed. By 2017, this rate had increased to 28.8 CDRs for every 100 ACDFs performed. This translates to CDRs representing $22.3 \%$ of all singlelevel anterior cervical procedures performed for radiculopathy and/or myelopathy in the year 2017 (Fig. 1). The break point in the rate of proportional CDR utilization occurred between 2012 and 2013. The proportion nearly doubled, from 6.0 cases per 100 ACDFs in 2012 to 10.2 cases per 100 ACDFs in 2013.

\section{Regional Trends}

While utilization increased substantially overall, there were notable discrepancies at the regional level (Table 2 and Fig. 2). Between 2009 and 2017, the US Census division with the highest average utilization of CDR was the Mountain region (Arizona, Colorado, Idaho, Montana, Nevada, New Mexico, Utah, and Wyoming), where 14.3 CDRs were performed for every 100 ACDFs. This is in contrast to the East South Central region (Alabama, Kentucky, Mississippi, and Tennessee), where only 2.1 CDRs were performed for every 100 ACDFs.

\section{Patient Characteristics}

Patient case mix may account for some of this regional discrepancy. To account for the potential confounding influence of regional distribution of patient characteristics, a mixed-effects regression model was constructed to adjust the regional estimates by individual patient-level characteristics (Table 3). It can be seen that significant associations exist between the odds of undergoing a CDR and

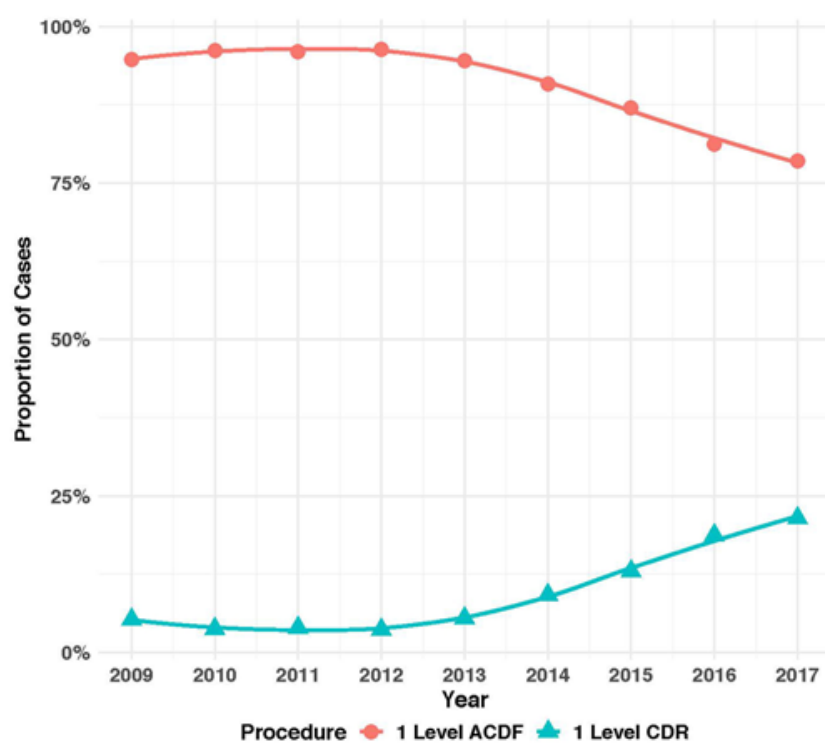

FIG. 1. Graph showing changes in proportional utilization of single-level CDR compared to ACDF between 2009 and 2017. Significant temporal change occurred (chi-square $=6.4 ; p=0.01$ ). Data from the MarketScan Research Databases, 2009-2017 $(n=47,387)$. Figure is available in color online only.

patient age, neurological findings, and Charlson Comorbidity Index score.

After accounting for case-mix differences between regions, significant differences in the uptake of CDR remained evident (chi-square $=830.4 ; p=0.001$ ). A patient in the Mountain, Pacific, West South Central, or South Atlantic region appears to have a significantly greater likelihood

TABLE 2. CDR utilization by region of surgery for 46,199 patients

\begin{tabular}{|c|c|c|c|c|}
\hline \multirow[b]{2}{*}{ US Census Region } & \multicolumn{2}{|c|}{$\begin{array}{c}\text { No. of } \\
\text { Patients }\end{array}$} & \multirow{2}{*}{$\begin{array}{c}\text { Proportional } \\
\text { Utilization } \\
\text { (CDRs/100 ACDFs } \\
\text { performed) }\end{array}$} & \multirow{2}{*}{$\begin{array}{c}p \\
\text { Value }^{*}\end{array}$} \\
\hline & CDR & ACDF & & \\
\hline & & & & $<0.001$ \\
\hline East North Central & 495 & 8,366 & 5.6 & \\
\hline East South Central & 117 & 5,543 & 2.1 & \\
\hline Middle Atlantic & 216 & 3,411 & 6.0 & \\
\hline Mountain & 355 & 2,024 & 14.9 & \\
\hline New England & 51 & 1,599 & 3.1 & \\
\hline Pacific & 452 & 2,831 & 13.8 & \\
\hline South Atlantic & 870 & 10,233 & 7.8 & \\
\hline West North Central & 195 & 2,388 & 7.5 & \\
\hline West South Central & 714 & 6,337 & 11.3 & \\
\hline
\end{tabular}

Data were derived from the MarketScan Research Databases for years 20092017. There were 1188 patients $(2.5 \%$; 88 who had CDR and 1100 who had ACDF) with an unknown region of surgery, and these patients were excluded from the regional analysis). Thus, the total number of patients was 46,199 rather than 47,387. See Fig. 2 for a description of the US Census regions.

* The chi-square testing of the equality of proportions across regions showed statistically significant differences $(p<0.001)$. 


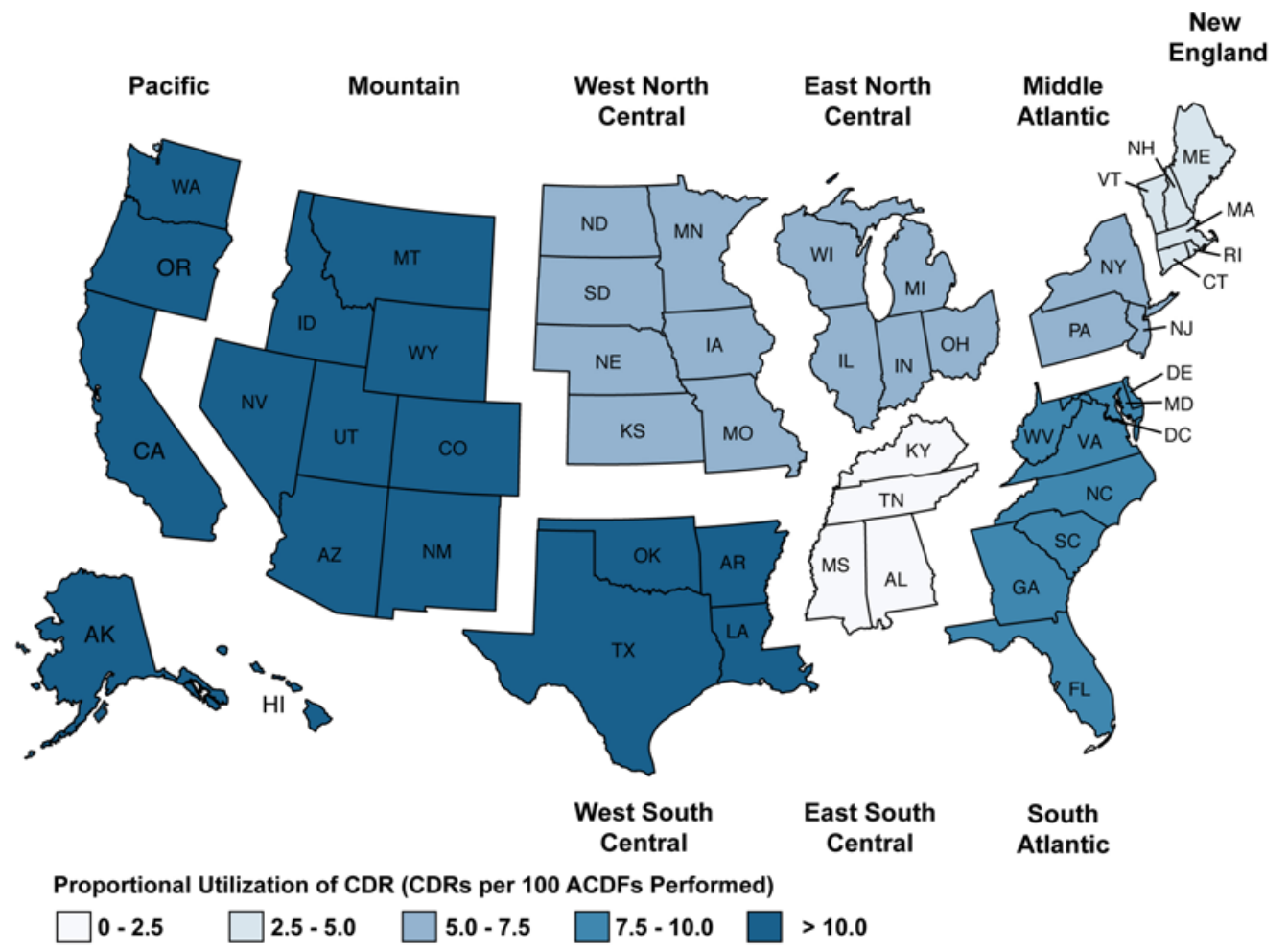

FIG. 2. Regional differences in proportional utilization of CDR relative to ACDF. Utilization is reported as number of CDR cases per 100 ACDFs by US Census region. Data from the MarketScan Research Databases, 2009-2017 ( $n=46,199)$.

of undergoing CDR compared with the average, while a patient in the East North Central, New England, or East South Central region appears to have a significantly lower likelihood than the average of undergoing CDR (Fig. 3).

\section{Discussion}

This analysis of US commercial insurance provider data provides descriptive epidemiology of the single-level CDR for symptomatic cervical spondylotic pathology in the US. Our analysis of 47,387 cases from a nationwide sample of patients with employer-sponsored health insurance treated between 2009 and 2017 suggests that proportional utilization of CDR has increased substantially relative to the utilization of ACDF. The rate of uptake appears relatively stable between 2009 and 2012 and then begins to rise starting in 2013, with this trend continuing until the end of 2017. Notably, observed utilization rates varied across regions of the US.

Our finding of increased proportional utilization of CDR relative to $\mathrm{ACDF}$ is in agreement with a smaller study using data from the National Surgical Quality Improvement Program database. ${ }^{11}$ The authors of that study reported on a total of 1102 patients treated between 2010 and 2016 who underwent a single-level procedure for cervical radiculopathy. They found a relative increase in CDR procedures over this time period, from a rate of $7.7 \%$ to one of $16.1 \%$. Furthermore, our finding that substantial increases in utilization did not occur prior to 2013 is in agreement with a study by Saifi et al. in which they as- sessed trends in CDR utilization between 2006 and 2013, based on the National Inpatient Sample. ${ }^{15}$ These authors found only a modest increase in CDR procedures, from $0.45 \%$ in 2006 to $1.23 \%$ in 2013.

The reasons for the acceleration in uptake in 2013 are unclear. It is possible that the trend reflects the increasing availability of the devices, as more companies develop and market their own versions of artificial cervical discs. Prior to 2012, only 3 artificial cervical disc devices had obtained FDA approval: the Prestige ST Cervical Disc (Medtronic), the ProDisc-C (Synthes Spine), and the Bryan Cervical Disc (Medtronic)..$^{17,20,22}$ During the period 2012 to 2014, 4 more discs were approved: the Secure-C Cervical Artificial Disc (Globus), the PCM Cervical Disc (NuVasive), the Mobi-C (Zimmer Biomet), and the Prestige LP Cervical Disc (Medtronic). ${ }^{18,19,21,23}$ This influx of artificial cervical disc devices into the US market between 2012 and 2014 may have brought greater attention to the technology and prompted the increasing trends in utilization. Moreover, surgeons' awareness of the mounting evidence in support of the devices may in part explain the changing trends as well. A number of papers based on the FDA Investigational Device Exemption studies with long-term efficacy data (5 or more years of follow-up) were published in support of CDR during this period of rising utilization. . $3,4,8,14,26^{-14}$

Even after adjusting for potential confounding influences from differences in regional case mix, our data suggest that significant differences in proportional utilization remain between regions. Uptake of the CDR procedure appeared greatest in the Mountain and Pacific regions, while 
TABLE 3. Adjusted patient-level fixed-effects estimates for the odds of undergoing a CDR procedure from a two-level mixed-effects logistic regression model

\begin{tabular}{lcr}
\hline Patient-Level Characteristic* & OR $(95 \%$ Cl $)$ & p Value \\
\hline Age, yrs & & \\
\hline $18-40$ & $15.9(10.0,25.5)$ & $<0.001$ \\
\hline $40-50$ & $10.8(6.8,17.3)$ & $<0.001$ \\
\hline $50-65$ & $5.5(3.4,8.7)$ & $<0.001$ \\
\hline$>65$ & $($ Reference $)$ & \\
\hline Male & $1.0(1.0,1.1)$ & 0.356 \\
\hline No myelopathy & $1.5(1.4,1.7)$ & $<0.001$ \\
\hline Charlson Comorbidity Index score & & \\
\hline 0 & $2.7(1.7,4.2)$ & $<0.001$ \\
\hline 1 & $2.4(1.5,3.9)$ & $<0.001$ \\
\hline 2 & $1.8(1.1,3.1)$ & $<0.001$ \\
\hline$>2$ & $($ Reference $)$ & \\
\hline No osteoporosis & $1.2(1.0,1.5)$ & 0.079 \\
\hline Nonsmoker & $1.1(1.0,1.2)$ & 0.154 \\
\hline
\end{tabular}

Data were derived from the MarketScan Research Databases, 2009-2017 (n $=46,199$ ). Patient-level fixed effects were adjusted for region of surgery using a two-level mixed-effects logistic regression model that included a randomeffects covariate for region of surgery.

Boldface type indicates statistical significance.

* Reference for dichotomous variables: female, myelopathy/myeloradiculopathy, osteoporosis, and smoker, respectively.

it was lowest in the East South Central and New England regions. The reasons for this heterogeneous uptake are likely multifactorial, including surgeon preference and training, patient preference, hospital contracts with device manufacturers, and distribution of marketing efforts.

While this study provides a large sample of procedures performed in the US over a period of 9 years, it has limitations. Most notably, radiological parameters are not available in our insurance claims database. The surgical decision-making process is partly based on radiological factors, such as the presence of a collapsed, ankylosed intervertebral disc, significant facet arthrosis, ossification of the posterior longitudinal ligament, or dynamic instability on flexion-extension plain-film radiographs. ${ }^{10}$ These factors could not be controlled for in our multilevel regression model and may therefore confound the regional comparisons. However, we suspect that the substantial differences observed in CDR utilization among regions are unlikely to be solely attributable to radiological differences in patient populations. In addition, our study is reliant on administrative claims-based data. As with any study using data of this nature, coding errors are a potential source of inaccuracy. ${ }^{6}$ Our screening protocol included ICD-9 and ICD-10 diagnostic codes in combination with CPT codes, which may have helped mitigate this limitation. Using the combination raises the specificity but generally lowers the sensitivity for cervical spinal interventions. ${ }^{24,25}$ This suggests that certain cases may not be captured by our screening algorithm but that those that were included are likely to represent the procedure of interest. Additionally, we were limited in our ability to study geographic

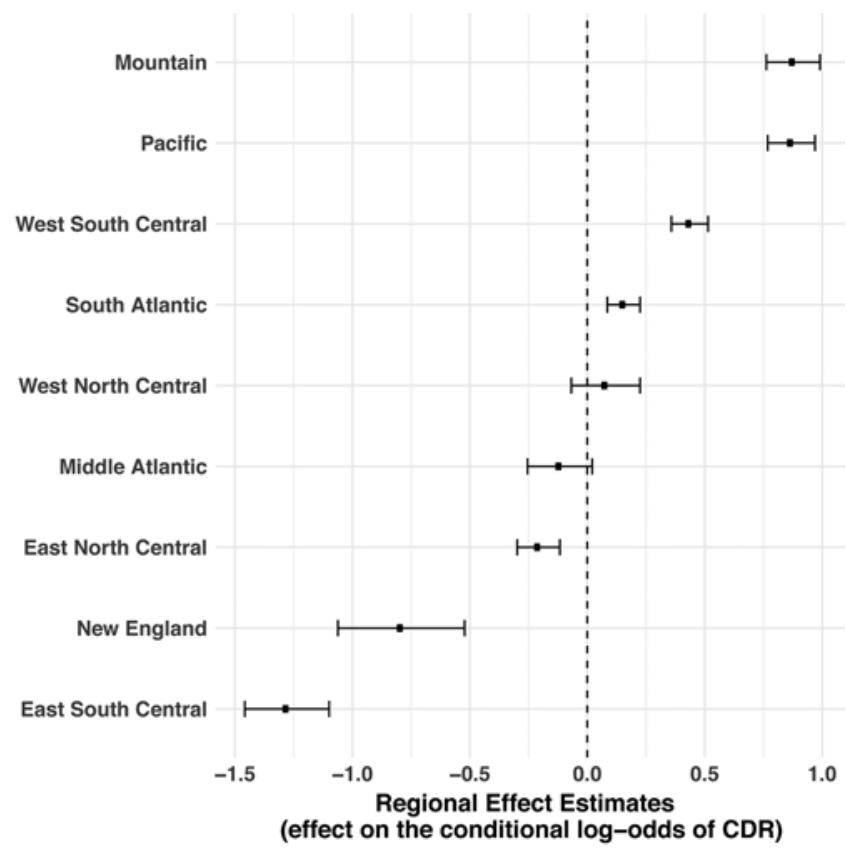

FIG. 3. Estimated regional effect sizes. Estimates based on a multilevel mixed-effects logistic regression model. The model included fixed effects for individual patient-level characteristics and a random effect for the region where the patient was treated. Values less than zero suggest lesser regional utilization of $C D R$, while values greater than zero suggest greater regional utilization compared with the national average. Data from the MarketScan Research Databases, 2009-2017 ( $n=46,199)$.

differences at a level more granular than regions. Our agreement with MarketScan limits the ability to publish state- or county-level data. As such, there may be further heterogeneity among states within the regions and likely even more heterogeneity among hospitals and among individual surgeons. Cultural practices within individual hospitals may limit the uptake of novel surgical devices among groups of surgeons. Additionally, individual surgeon perspectives on the utility and efficacy of these novel devices may also serve as barriers to uptake. Furthermore, we were unable to assess the approval processes of individual commercial insurance plans. It is possible that certain plans are less likely to approve the CDR procedure, thereby serving as a barrier to uptake. This may, in part, explain the temporal trends in utilization and the regional differences noted from our data. This will require further investigation; however, a study of this nature is likely to be hampered by data access agreements with insurance plans regarding case approval metrics. Finally, while these estimates in proportional utilization are derived from a very large sample of patients enrolled in private commercial insurance plans in the US, they do not necessarily reflect utilization across all strata of healthcare users. Most notably, those with Medicaid coverage were not included in this data set, nor were those with Medicare coverage who do not have supplementary private insurance coverage. Also, not all private commercial insurance providers are included in MarketScan. 


\section{Conclusions}

This nation-level study of private commercial insurance providers produced novel insights into the rate of uptake and regional differences in the utilization of singlelevel CDR. Overall, these data suggest a substantial rise in the utilization of CDR for symptomatic single-level cervical spondylotic pathology between 2009 and 2017. The increase appears to have begun in 2013 and continued thereafter, with uptake much stronger in some US regions than others. Further study will be needed to ascertain specific factors that predict adoption of this promising, emerging technology.

\section{References}

1. Aizcorbe A, Liebman E, Pack S, Cutler DM, Chernew ME, Rosen AB: Measuring health care costs of individuals with employer-sponsored health insurance in the U.S.: a comparison of survey and claims data. Stat J IAOS 28:43-51, 2012

2. Berchick ER, Hood E, Barnett JC: Health Insurance Coverage in the United States: 2017. U.S. Census Bureau, 2018 (https://www.census.gov/content/dam/Census/library/ publications/2018/demo/p60-264.pdf) [Accessed November 12, 2019]

3. Burkus JK, Haid RW, Traynelis VC, Mummaneni PV: Longterm clinical and radiographic outcomes of cervical disc replacement with the Prestige disc: results from a prospective randomized controlled clinical trial. J Neurosurg Spine 13:308-318, 2010

4. Burkus JK, Traynelis VC, Haid RW Jr, Mummaneni PV: Clinical and radiographic analysis of an artificial cervical disc: 7-year follow-up from the Prestige prospective randomized controlled clinical trial: clinical article. J Neurosurg Spine 21:516-528, 2014

5. Findlay C, Ayis S, Demetriades AK: Total disc replacement versus anterior cervical discectomy and fusion: a systematic review with meta-analysis of data from a total of 3160 patients across 14 randomized controlled trials with both short- and medium- to long-term outcomes. Bone Joint J 100-B:991-1001, 2018

6. Gologorsky Y, Knightly JJ, Lu Y, Chi JH, Groff MW: Improving discharge data fidelity for use in large administrative databases. Neurosurg Focus 36(6):E2, 2014

7. Hansen LG: The Truven Health MarketScan Databases for Life Sciences Researchers. Truven Health Analytics, IBM Watson Health, 2017 (https://truvenhealth.com/ Portals/0/Assets/2017-MarketScan-Databases-Life-SciencesResearchers-WP.pdf) [Accessed November 12, 2019]

8. Janssen ME, Zigler JE, Spivak JM, Delamarter RB, Darden BV II, Kopjar B: ProDisc-C total disc replacement versus anterior cervical discectomy and fusion for single-level symptomatic cervical disc disease: seven-year follow-up of the prospective randomized U.S. Food and Drug Administration Investigational Device Exemption Study. J Bone Joint Surg Am 97:1738-1747, 2015

9. Lanman TH, Burkus JK, Dryer RG, Gornet MF, McConnell J, Hodges SD: Long-term clinical and radiographic outcomes of the Prestige LP artificial cervical disc replacement at 2 levels: results from a prospective randomized controlled clinical trial. J Neurosurg Spine 27:7-19, 2017

10. Leven D, Meaike J, Radcliff K, Qureshi S: Cervical disc replacement surgery: indications, technique, and technical pearls. Curr Rev Musculoskelet Med 10:160-169, 2017

11. Mok JK, Sheha ED, Samuel AM, McAnany SJ, Vaishnav AS, Albert TJ, et al: Evaluation of current trends in treatment of single-level cervical radiculopathy. Clin Spine Surg 32:E241-E245, 2019
12. Mummaneni PV, Burkus JK, Haid RW, Traynelis VC, Zdeblick TA: Clinical and radiographic analysis of cervical disc arthroplasty compared with allograft fusion: a randomized controlled clinical trial. J Neurosurg Spine (Phila Pa 1976) 6:198-209, 2007

13. Nunley PD, Coric D, Frank KA, Stone MB: Cervical disc arthroplasty: current evidence and real-world application. Neurosurgery 83:1087-1106, 2018

14. Phillips FM, Geisler FH, Gilder KM, Reah C, Howell KM, McAfee PC: Long-term outcomes of the US FDA IDE prospective, randomized controlled clinical trial comparing PCM cervical disc arthroplasty with anterior cervical discectomy and fusion. Spine (Phila Pa 1976) 40:674-683, 2015

15. Saifi C, Fein AW, Cazzulino A, Lehman RA, Phillips FM, An HS, et al: Trends in resource utilization and rate of cervical disc arthroplasty and anterior cervical discectomy and fusion throughout the United States from 2006 to 2013. Spine J 18:1022-1029, 2018

16. United States Census Bureau: Census Regions and Divisions of the United States (https://www2.census.gov/geo/ pdfs/maps-data/maps/reference/us_regdiv.pdf) [Accessed November 12, 2019]

17. United States Food \& Drug Administration: Summary of Safety and Effectiveness Data: Bryan Cervical Disc. 2009 (https://www.accessdata.fda.gov/cdrh_docs/pdf6/P060023b. pdf) [Accessed November 12, 2019]

18. United States Food \& Drug Administration: Summary of Safety and Effectiveness Data: Mobi-C Cervical Disc Prosthesis. 2013 (https://www.accessdata.fda.gov/cdrh_docs/ pdf11/p110002b.pdf) [Accessed November 12, 2019]

19. United States Food \& Drug Administration: Summary of Safety and Effectiveness Data: PCM Cervical Disc. 2012 (https://www.accessdata.fda.gov/cdrh_docs/pdf10/P100012B. pdf) [Accessed November 12, 2019]

20. United States Food \& Drug Administration: Summary of Safety and Effectiveness Data: Prestige Cervical Disc System. 2007 (https://www.accessdata.fda.gov/cdrh_docs/ pdf6/P060018b.pdf) [Accessed November 12, 2019]

21. United States Food \& Drug Administration: Summary of Safety and Effectiveness Data: Prestige LP Cervical Disc. 2014 (https://www.accessdata.fda.gov/cdrh_docs/pdf9/ P090029B.pdf) [Accessed November 12, 2019]

22. United States Food \& Drug Administration: Summary of Safety and Effectiveness Data: ProDisc-C Total Disc Replacement. 2007 (https://www.accessdata.fda.gov/cdrh docs/pdf7/p070001b.pdf) [Accessed November 12, 2019]

23. United States Food \& Drug Administration: Summary of Safety and Effectiveness Data: Secure-C Cervical Artificial Disc. 2012 (https://www.accessdata.fda.gov/cdrh_docs/ pdf10/p100003b.pdf) [Accessed November 12, 2019]

24. Wang MC, Laud PW, Macias M, Nattinger AB: Strengths and limitations of International Classification of Disease Ninth Revision Clinical Modification codes in defining cervical spine surgery. Spine (Phila Pa 1976) 36:E38-E44, 2011

25. Wang MC, Laud PW, Macias M, Nattinger AB: Utility of a combined Current Procedural Terminology and International Classification of Diseases, Ninth Revision, Clinical Modification code algorithm in classifying cervical spine surgery for degenerative changes. Spine (Phila Pa 1976) 36:1843-1848, 2011

26. Zigler JE, Delamarter R, Murrey D, Spivak J, Janssen M: ProDisc-C and anterior cervical discectomy and fusion as surgical treatment for single-level cervical symptomatic degenerative disc disease: five-year results of a Food and Drug Administration study. Spine (Phila Pa 1976) 38:203-209, 2013

\section{Disclosures}

Dr. Traynelis reports being a consultant for Medtronic and NuVa- 
Witiw et al.

sive; being a patent holder with Medtronic; and receiving clinical or research support for the present study from NREF.

\section{Author Correspondence}

Conception and design: Witiw. Acquisition of data: Ham. Analysis and interpretation of data: Witiw. Drafting the article: Witiw.

Critically revising the article: all authors. Reviewed submitted version of manuscript: all authors. Approved the final version of the manuscript on behalf of all authors: Witiw. Statistical analysis: Witiw. Administrative/technical/material support: Smieliauskas, Traynelis.

\section{Supplemental Information}

Online-Only Content

Supplemental material is available with the online version of the article.

Supplementary Table 1. https://thejns.org/doi/suppl/10.3171/ 2019.10.SPINE19919.

\section{Correspondence}

Christopher D. Witiw: St. Michael's Hospital, Toronto, ON, Canada.christopher.witiw@unityhealth.to. 